International Journal of Social Science and Economic Research

ISSN: 2455-8834

Volume:06, Issue:06 "June 2021"

\title{
IMPACT OF DIGITALIZATION ON MENTAL WELLNESS OF STUDENTS
}

\author{
YASHASVI PAWAR
}

Delhi Public School Sushant Lok

DOI: 10.46609/IJSSER.2021.v06i06.014 URL: https://doi.org/10.46609/IJSSER.2021.v06i06.014

\begin{abstract}
Currently, we are living in a modern developing world, where new steps are taken every day towards a more technology-based future. Technologies surround us, and they have become a significant part ofour everyday lives. Even for young children, digital electronics like phones and laptops are an undeniable necessity; these devices hold great potential for transforming learning. In this world of digitalization, the Internet provides infinite knowledge and endless opportunities to children; it is also furnishing more stress and anxiety on their minds and possibly even limiting their imagination and promoting aggressiveness and cognitive deformities. Personality disorder or psychological issues faced by adults can be rooted back to mental health issues developed in their childhood. Therefore, it is vital to understand the effects of this new digital world on children's mental well-being. Research conducted in this paper was in the form of a review of available literature research to provide an overview of how digitalization influences different aspects of children's mental or psychological well- being. Based on the research, digitalization has its list of pros and cons. However, the cons can destroy children's developing young minds, and it is necessary to take some steps to address the 'side effects' of the Internet.
\end{abstract}

KEYWORDS: Digitalization, Personality development, Mental well-being, Children, Internet.

\section{INTRODUCTION}

From online gaming to online classes to online meetings, digital media has a firm grip on the world. The machines are controlling the mindset, as it makes everybody dependent on them. IT world has made an enormous impact globally in the last 20 years, but this impact had gotten a lot more intense recently when WHO declared COVID-19 as a global pandemic. The pandemic led to a lockdown in almost every country, which resulted in popularized digital education. Digital Education is a growing concept. Digital Education has both negative and positive effects on young minds. Students are happywith flexible hours; it has also helped institutes increase enrollments. 


\section{International Journal of Social Science and Economic Research}

ISSN: $2455-8834$

Volume:06, Issue:06 "June 2021"

Other than online classes, the overall Internet and social media have also impacted children's psychology. Young children and youth are more vulnerable to the Internet and technological addiction. Internet addiction refers to the compulsive need to spend a great deal of time on the Internet to the point where every aspect of one's life, such as health, relationships, etc., suffers. But on the other hand, it is seen to have an adverse result on the mental well-being of the students. Internet addicts try to fillsome void in their lives by creating a life according to their preferences. Some might also try and escape reality. Different authors characterize generations whose active socialization is based on the digital world as "digital generation" and even "digital natives" (Palfrey, \& Gasser, 2011).

Even though an increase in the use of modern technology implies a brighter, more innovative future of better social relations, more advanced technology, and less work burden, it also promotes some significant problems such as increased stress and anxiety, internet addiction, and other numerous personality types disorders. As a result, the world we are in sometimes raises questions like whether we should ignore these problems as collateral to have a more technological-based advanced future or how we can address these problems on a worldwide level.

Lack of research on how the Internet is associated with different psychological symptoms and disorders creates uncertainty on numerous topics. Some mental health experts have expressed concerns that excessive use of the Internet can negatively impact and contribute to psychiatric symptoms (Bremer, 2005). Raised number of complaints on increased mental disorders due to more than the average Internet has also raised concern among experts and society.

\section{Cyberpsychology - A new Concept}

Defined as the discipline of understanding the psychological processes related to, and underlying, all aspects and features of technologically interconnected human behavior (AtrillSmith et al., 2019), cyberpsychology includes multiple intersecting disciplines human-computer interaction, computer science, engineering, and psychology. Professor John Suler is the founder of this discipline. Suler draws on a vast range of theoretical constructs in psychology, including psychodynamic theory, operant theory, group dynamics theory, and theories of human motivation. Professor Suler had a different approach to understanding the Internet's influence on the human psyche; he had a unique approach to exploring experiences in cyberspace and has applications in a wide range of fields like online communication and consumer psychology. His dedication and imagination led him to create cyberpsychology as an established, respected field that is slowly and steadily catching attention from all around the globe.

As of the fourth quarter of 2020, there are 4.66 billion active internet users (Datareportal, 2020). 
A significant increase is visible in the population of "digital natives"; this generation is growing up with gadgets like computers and smartphones and has transformed how children perceive information and socialize with the real world. When children learn to understand the world around them and develop fundamental social and cognitive skills, children are instead catapulted into cyberspace. The increased exposure to screens has impacted children's perception of our natural environments. As society's dependency on machines increases, the variance between the real world and the digital world keeps on diminishing; this is where cyberpsychology plays its part. As total removing Internet or gadgets from houses is not a possibility, steps can be taken into educating parents and the society about the impactsof the Internet. Even though it might be a new concept for parents to grasp as they weren't grown in aworld full of gadgets, it is necessary for the proper development of the children.

The graph below shows the internet Users Distribution globally, and the numbers are shocking and onthe rise. Nevertheless, the field of cyberpsychology remains open to refinement, including an inquiry into the nature of current and future trends in mental illness associated with technological advances.

\section{Internet Users Distribution in the World - 2021}
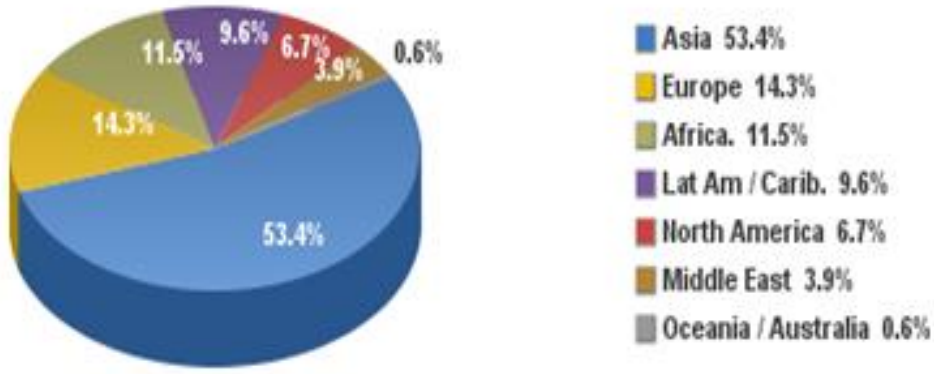

Source: Internet World Stats - wWw.internetworldstats. com/stats.htm Basis: 5,168,780,607 Internet users in March 31, 2021 Copyright @ 2021, Miniwatts Marketing Group

(GRAPH 1)

\section{Internet and Personality}

Digitalization can be seen to have an impact on many aspects of your life, including your personality. Even though research on the cognitive, social, psychological, and physical implications of using the Internet for children and adolescents remains unanswered (Jackson, 2008), it can be observed that Internet influence some aspect of personalities like hyperactivity, 


\section{International Journal of Social Science and Economic Research}

ISSN: $2455-8834$

Volume:06, Issue:06 "June 2021"

anxiety, depression, and many more.

Hamburger and Ben-Artzi are the first ones who analyzed an association between the Internet and Personality. The result of their study was quite interesting as they confirm earlier studies showing thatwomen have higher self-awareness and are more likely to use the social network for support. The Internet also has a constructive impact on children as it helps develop abstract and logical thinking, is a good way of self-education, and enhances research skills. However, on the downside, the Internet can promote aggressive or irritable behavior, give children wrong ideas about the real world, and develop problems handling social situations, and impaired communication. Excessive Internet use could lead to Internet addiction characterized by one's inability to inhibit Internet use despite adverse effects on many domains of life, such as academic performance, social relations, physical and mentalhealth, and quality of life.

Numerous cases indicate that some active Internet users (that is, people using the Internet more than afew hours a day for non-work-related activities) suffer from mental disorders (Treuer et al., 2001; Iftene et al. Al., 2004, Kendall, 2015).

A study by Salwa Abdullah portrayed that excess use of gadgets can have several negative impacts onchildren. A positive correlation between the Internet and psychological development (aspects like emotional symptoms, peer- relation, inattention, hyperactivity, and other behavioral problem) can be seen in children of various ages. Difficulty with communication, lack of desire to help others, and all other effects, indicates a direct relationship between the Internet and the mental well-being of children. Interestingly the results in the study also portrayed that boys were more dependent on the Internet than girls. High indicators of the mental health criteria presented in the study, in addition to prosocial behaviors, can cause a child's personality disorder. As the usage of gadgets and the internet increases, so does the chances of being psychologically ill. Below is a table from the study that showcases correlation among different aspects of psychology and the Internet.

Table- Correlation between categories of Internet dependence and psychological characteristics

\begin{tabular}{|l|c|c|c|}
\hline \multicolumn{1}{|c|}{ Variables } & Normal & Boardline & Addict \\
\hline Emotional symptoms & .51 & .55 & .83 \\
\hline Behavioural Problems & .53 & .61 & .82 \\
\hline Hyperactivity & .62 & .49 & .69 \\
\hline Prosocial behaviour & .59 & .52 & .83 \\
\hline Peer ralationship & .71 & .63 & .84 \\
\hline
\end{tabular}

$* 0>0.5$ 
International Journal of Social Science and Economic Research

ISSN: 2455-8834

Volume:06, Issue:06 "June 2021"

\section{The results of the relationship criterion of The Strengths and Difficulties Questionnaire (SDQ) and the level of Internet addiction.}

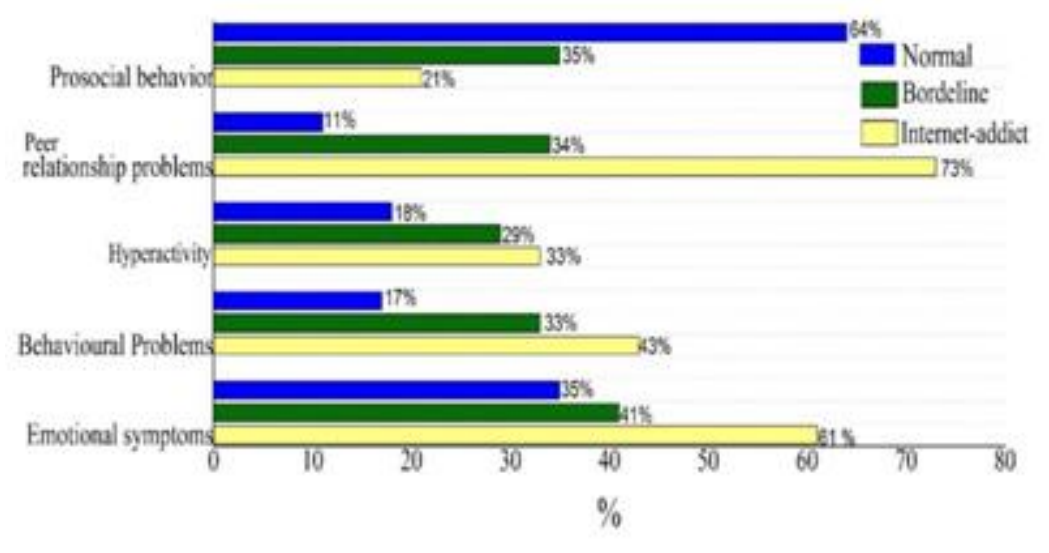

(GRAPH 2)

Some limitations of the literature available are that the samples of the studies are limited and hard to apply at a global level. Not considering the context of content that the children watch on the Internet can also influence the study results. In addition, sometimes, the research method is not appropriate oropen to wrongful interpretation and bias, which can question the authenticity of the study. However, limitations do not necessarily render paper invalid; limitations suggest scope for even better and accurate results.

Personality is the source of our emotions, cognition, and behavior. We can compare our personality structure to that of an iceberg, of which only the tip is visible above the water level, and the rest of its vast mass is hidden underneath. The influence of digitalization on you is in your hand; it will only hurtif you give it the power to do so.

\section{Gaming And Psychological Development}

Different effects of gaming on children's psyche are still a debatable topic in the field of research. Developing computer games for children is an excellent way of self-education; using the Internet can become a good school of communication and skills in searching and selecting information (Chen, 2014). Gaming has an impact on one's emotional vulnerability. When you accomplish your goals in a video game or the sensation when you lose, the feeling you get is the secret that helps companies reachmillions of sales. And this feeling of accomplishment can soon turn a hobby into an addiction. Studies show that gaming has several upsides, including a higher level of critical thinking skills, better virtualsocial interaction, emotional resilience, and complex problem-solving skills. 
Video Games are not vicious, however problematic and excessive video gaming can cause psychological damage and addiction. Children, especially teenagers, tend to use video games to escape their problems; they can also use games to suppress emotions and avoid dealing with a real-life crisis. These circumstances can lead to a severe impact on your mental being and can even lead to severe depression.

Some studies indicate that gaming results in people becoming anxious, depressed, angry, or even violent and have low self-esteem. Unfortunately, nearly three decades of research exploring the possible links between video games and adverse outcomes, including aggression, addiction, wellbeing, and cognitive functioning, have brought us nowhere near a consensus or evidence-based policybecause reliable and naturally valid studies are few and far between.

The American Psychiatric Association did not identify any psychiatric conditions related to video games in the Diagnostic and Statistical Manual of Mental Disorders (DSM-5). Still, it does recommendInternet Gaming Disorder as a topic for further research. The kind of impact gaming like have on children will also be influenced by their playing games. For example, playing a game with violent imaging might increase violent behavior in a child or make them insensitive to their environment andlead to an emotional problem.

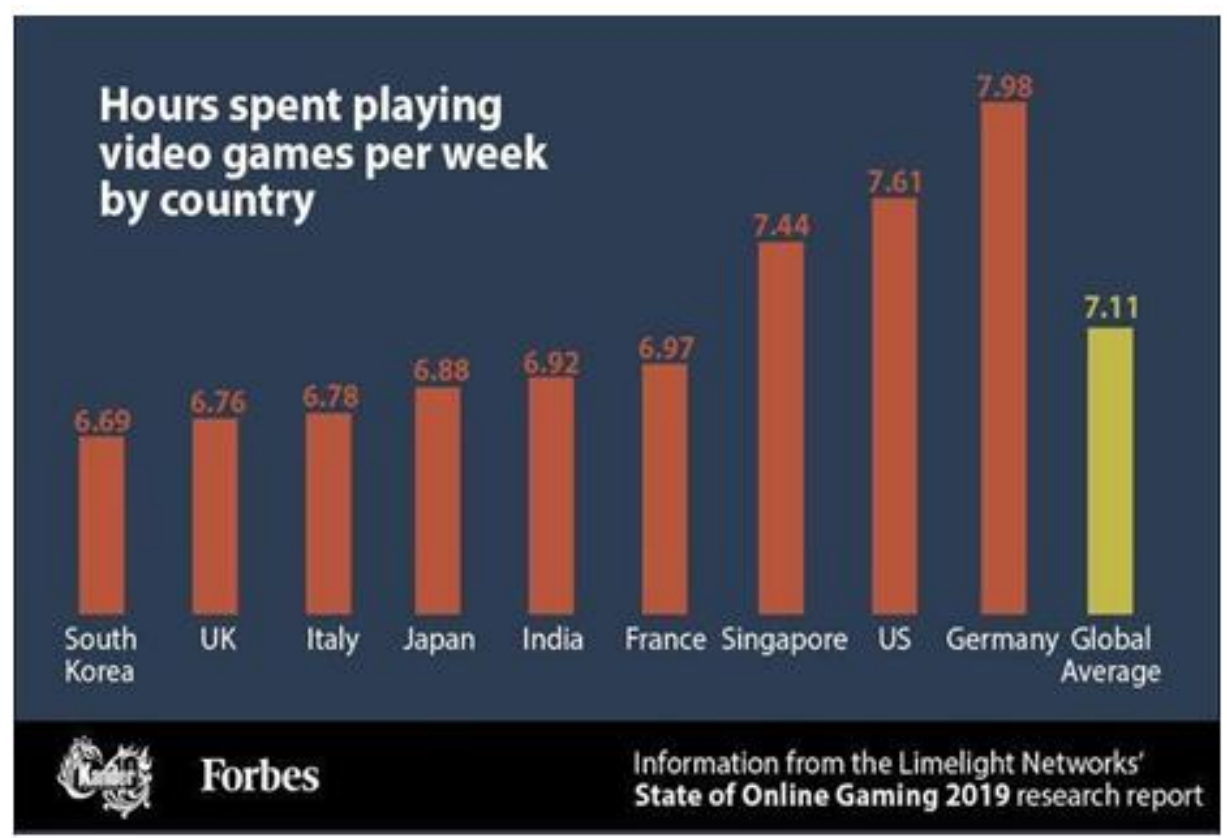

(GRAPH 3) 


\section{International Journal of Social Science and Economic Research}

ISSN: 2455-8834

Volume:06, Issue:06 "June 2021"

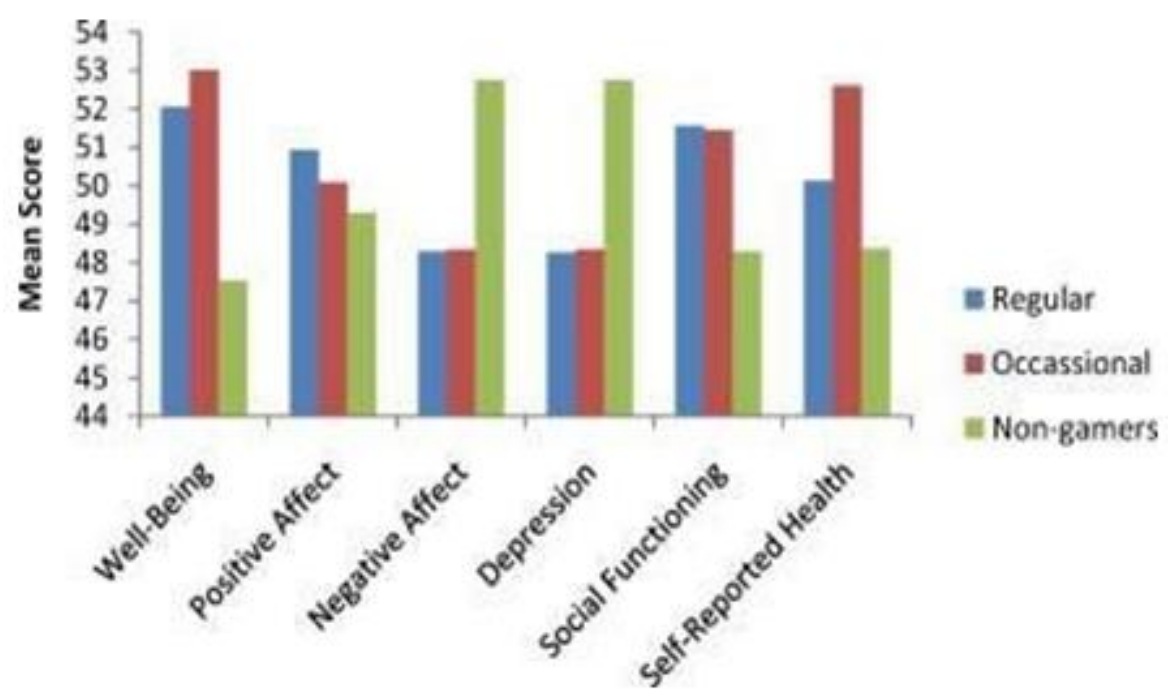

(GRAPH 4)

The available literature that links gaming and its impact on mental health are vague and negligible in quantity. And limitations like not considering the amount of time spent on games and the type of games played by the children are seen. Also, sometimes inadequate amount of volunteers in studies is an issue. Nevertheless, this issue requires more attention and better assessment to address the problems faced by children.

\section{Social Media And Developing Minds}

One of the most popular social media sites, Instagram alone, has almost 30 crore users under age 18. Surveys show that ninety percent of teens ages 13-17 have used social media. Seventy-five percent report having at least one active social media profile, and $51 \%$ report visiting a social media site daily. Two-thirds of teens have their own mobile devices with internet capabilities.

Social media is defined as a form of electronic communication through which users create online communities to share information, ideas, personal messages, and other content. Over the past two decades, social media usage has been significantly increasing, especially among the youth. This growing use has also raised concern among the experts and the parents. As a result, research on socialmedia and adolescent mental health has increased in recent years. Many studies explore whether more frequent social media use is associated with mental health concerns, including depression, body image concerns, disordered eating, and externalizing problems. Both positive and negative effects of social media on youth's mental health can be calculated. However, the 


\section{International Journal of Social Science and Economic Research}

ISSN: $2455-8834$

Volume:06, Issue:06 "June 2021"

adverse effects outnumber the positiveimpact.

Social media helps you make new valuable connections, build relationships, and also helps you maintain your existing friendships. It also enables you to create awareness and share your expertise - also available possibilities for humor and entertainment, identity exploration, and creative expression. The receipt of online social support may also play a protective role for youth with mental illness. As the usage of social among youth increases, so does emotional and social dependency on these apps. At the same time, nearly every 1 in 5 adolescents is suffering from some mental disparities; this raises concern as the children's future is affected. On the Darker side of social media, we have matters like cyber-bullying, online harassment, body shaming, emotional suppression, and other such issues that can have a traumatic impact on children and cause severe mental problems. This can also can make children take questionable or regretful actions.

\section{U.S. Teens Have Mixed Feelings About Social Media \\ $\%$ of U.S. teens saying social media has a mostly positive/negative effect on people their age}

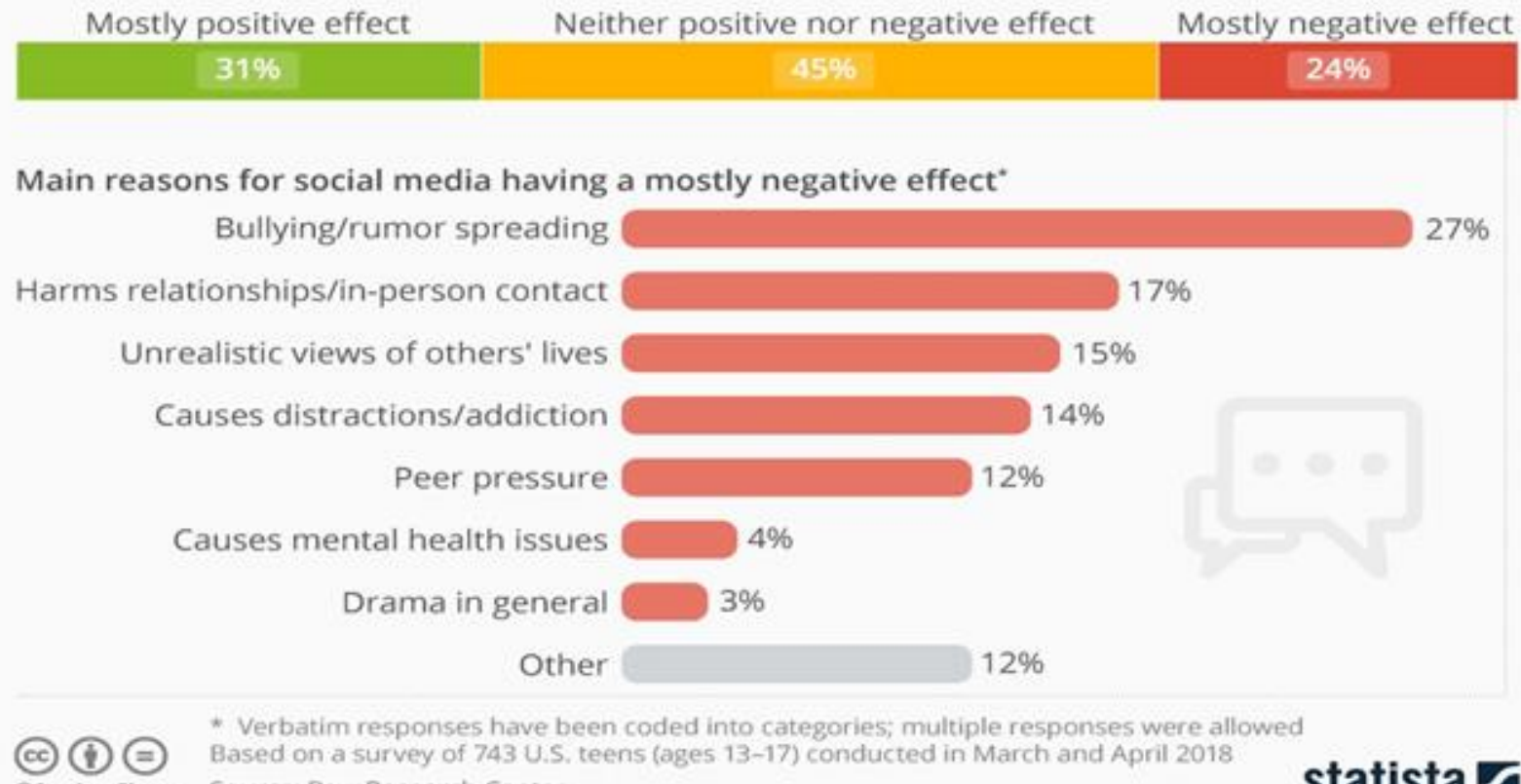

\section{(GRAPH 5)}

Using various types of social media depends on the kind of risk, a teen's use of the media, and the psychological makeup of the teen using them. Actions should be taken by parents as well as social media companies to help children keep healthy. Restriction on specific content, age 
International Journal of Social Science and Economic Research

ISSN: 2455-8834

Volume:06, Issue:06 "June 2021"

restriction while making accounts, parental consent, and many other steps can be taken to keep children safe. It is also vitally important to normalize and promote talking about mental health issues faced by the adolescents.

\section{Bibliography}

1. Salwa Abdullah Al Majali, 2020. The Digital World for Children and its Relationship withPersonality Disorders: Exploring Emerging Technologies. https://onlinejournals.org/index.php/i- jet/article/view/11412

2. Educating 21st Century Children : Emotional Well-being in the Digital Age https://doi.org/10.1787/b7f33425-en

3. Bremer, J., 2005. The Internet and children: advantages and disadvantages. Child Adolesc. Psychiatr. Clin. N. Am. 14 (3), 405-428. https://doi.org/10.1016/j.chc.2005.02.003

4. The Digital Addiction Scale for Children: Development and Validation . Nazir S. Hawi, EdD,1Maya Samaha, PhD,1 and Mark D. Griffifiths, PhD2. https://www.liebertpub.com/doi/pdf/10.1089/cyber.2019.0132

5. Impact of Social Media on Mental Health of Adolescents. Dr. Ramandeep Kaur* \& HilalBashir., 2015. http://ijoe.vidyapublications.com/Issues/Vol5/Vol5-4.pdf

6. How does the time children spend using digital technology impact their mental wellbeing,social relationships and physical activity? An evidence-focused literature review,2017.https://www.unicefirc.org/publications/925-how-does-the-time-children-spend-using-digital- technologyimpact-their-mental-well.html

7. The Impact of Social Media on Youth Mental Health: Challenges and Opportunities JacquelineNes, 2020. https://www.researchgate.net/publication/339706988_The_Impact_of_Social_Media_on_ Youth_Me ntal_Health_Challenges_and_Opportunities.

8. Digital Education: Opportunities and Threats. Sarbtej Singh1, Dr. Satish Kumar2, Dr.SorabhLakhanpal, 2020. https://ejmcm.com/?_action=export\&rf=idc\&issue=125

9. Psychology of the Digital Age: Humans Become Electric (Cambridge U Press,2016) https://www.researchgate.net/publication/285591590_Psychology_of the_Digital_Age Humans Become Electric Cambridge U Press 2016

10. Aggregated Roles of Smartphones in Young Adults' Leisure and Well-Being: A Diary Study Anna Irimiás, Tamás Csordás , Kornélia Kiss and Gábor Michalkó, 2021. 
International Journal of Social Science and Economic Research

ISSN: 2455-8834

Volume:06, Issue:06 "June 2021"

https://www.mdpi.com/2071-1050/13/8/4133

11. Johannes N, Vuorre M, Przybylski AK. 2021 Video game play is positively correlated withwell-being. R. Soc. Open Sci. 8: 202049.

https://doi.org/10.1098/rsos.202049

12. Embracing Digitalization: Student Learning and New Technologies William F.

Crittenden ,Isabella K.Biel ,and William A. Lovely III, 2018.

https://journals.sagepub.com/doi/abs/10.1177/0273475318820895

13. Relationship between Internet Using Mental health of Internet Users Dr. Hossain Jenaabadi, Mohammad Mojtaba Keikhayfarzaneh, 2011.

https://www.ijser.org/paper/Relationship-between- Internet-Using-Mental-health-ofInternet-Users.html

14. The impact of Internet interactivity and need for closure on consumer preference Yair Amichai-Hamburger*, Adi Fine, Abraham Goldstein, 2004.

https://www.sciencedirect.com/science/article/abs/pii/S0747563203000414

15. Cyberpsychology: Defining the Field Defining the transdisciplinary nature of cyberpsychology in a new era Julie R. Ancis, Ph.D, 2020.

https://www.psychologytoday.com/us/blog/the-cyberpsychologypage/202011/cyberpsychology-defining-the-field

16. The Internet's effect on personality traits: An important casualty of the "Internet addiction"paradigm. Elias Aboujaoude, 2017. https://www.ncbi.nlm.nih.gov/pmc/articles/PMC5573001/ 